Gut, 1963, 4, 344

\title{
Haemorrhage from peptic ulcer treated by continuous intragastric milk drip and early generous feeding
}

\author{
D. W. AShBY, J. ANDERSON, AND M. J. T. PEASTON \\ From the Gateshead Group of Hospitals
}

EDITORIAL SYNOPSIS Early feeding by means of an intragastric milk drip has been practised in a group of $\mathbf{4 2 5}$ patients admitted to a regional hospital with bleeding peptic ulcers. A low overall mortality of $4.9 \%$ was achieved even though more than a quarter of the patients treated were more than 60 years old. The fallacies in comparing mortalities from gastrointestinal bleeding are discussed and the need for adequate blood transfusion, early diagnosis, and medico-surgical collaboration emphasized.

A continuous intragastric milk drip was introduced for the relief of ulcer pain by Dr. Winkelstein of the Mount Sinai Hospital (Winkelstein, 1933). As it can be given easily to sleeping patients throughout the night it is strange that those who believe in early generous feeding of peptic ulcer after haemorrhage are not more ready to adopt this method for the initial treatment of haematemesis and melaena. This treatment was being used in the United Kingdom by Dr. Ernest Bulmer in Birmingham in 1946 and we have used it in the Gateshead Group of Hospitals from 1950 to the present. Its main theoretical advantages are that it supplies fluid, electrolytes, and protein, neutralizes acid, diminishes peptic activity, and prevents the contraction of the empty stomach. It pursues the principles of early generous feeding throughout the night, allowing approximately 2,000 calories in 24 hours as milk and as many as 4,000 calories when a Meulengracht diet is given in addition. Our technique of giving the drip has been virtually the same as Winkelstein's except that we use a soft latex tube instead of a Rehfuss tube and we add aluminium hydroxide instead of sodium bicarbonate. The milk is contained in vacolitre flasks and between 2.8 and 3.4 litres are dripped during 24 hours. For the whole of the first week the milk is

TABLE I

NUTRIENT VALUES OF INTRAGASTRIC MILK AS GIVEN IN THE FIRST WEEK ${ }^{1}$

Protein $\ldots \ldots \ldots \ldots \ldots \ldots \ldots \ldots \ldots \ldots \ldots \ldots . \ldots \ldots$ g. per 24 hours Carbohydrate........................ 150 ger 24 hours Calories $\ldots \ldots \ldots \ldots \ldots \ldots \ldots \ldots \ldots \ldots 1,950$ per 24 hours Sodium ..........................1.74 g. per 24 hours

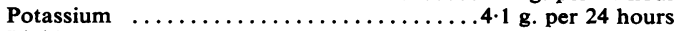

Fluids $\ldots \ldots \ldots \ldots \ldots \ldots \ldots \ldots \ldots \ldots \ldots, 2 \cdot 61$. litres water

1 This is in addition to the normal gastric diet. given continuously and thereafter the milk drip is erected only at night.

In 1955 one of us published a series of 100 cases treated with this method with a mortality of $7 \%$ (Ashby and Whitehouse, 1955). We were thus encouraged to increase the number of cases so treated until we can now produce a total of 425 cases with a mortality of $4.9 \%$. This compares well with present mortalities in Great Britain and we feel that at least some of the credit can be ascribed to the generous feeding regime.

\section{POSSIBLE CONTRAINDICATIONS TO THE INTRAGASTRIC MILK DRIP}

We do not give this therapy to patients known to be bleeding from oesophageal varices or who have suspected perforation, known pyloric stenosis, acute dilatation of the stomach, or ileus. The unsuspected stenosis can be detected by regular aspiration of the excess of gastric residue at intervals determined by the clinical condition of the patient. Diagnostic aspiration is important during the first 24 to 48 hours in order to establish an early indication of fresh bleeding. In the majority of patients pulse and blood pressure are normal on the second day and they are then able to sit up comfortably without inconvenience from the milk drip and are ready to receive light meals. In our experience acute dilatation of the stomach or ileus is rare and is more frequently encountered in patients who have had severe haemorrhage coupled with a period of starvation and aspiration and who are in any case likely candidates for surgery. Should signs of ileus develop the milk drip is withdrawn and treatment is continued with gastric aspiration, intravenous fluid, and blood, 
particular attention being given to electrolyte imbalance.

\section{STANDARDS FOR REPORTING MORTALITY DUE TO HAEMORRHAGE FROM PEPTIC ULCER}

Authors on both sides of the Atlantic frequently complain that it is difficult to compare published mortalities from ulcer haemorrhage and much of this difficulty stems from failure to adopt uniform standards of reporting, particularly as regards the exclusion of cases. In Great Britain the matter has been clarified by a Goulstonian lecture given by Dr. Avery Jones to the Royal College of Physicians in which he laid down very strict standards for reporting haemorrhage from ulcers (Avery Jones, 1947). Briefly, all mortality directly due to the haemorrhage or its management or to surgical intervention during admission for haemorrhage must be reported. Some authors at the beginning of the century excluded patients who were transferred to the surgical wards, others excluded deaths clearly related to the management of haemorrhage, such as those due to pulmonary oedema. In fact the only permissible exclusions are deaths directly due to some clearly unrelated disease such as pulmonary tuberculosis or deaths occurring after surgery in patients who have already fully recovered from haemorrhage, gone out of hospital, and returned to have an elective operation (Avery Jones, 1947). One must also include not only patients who die in the surgical wards but those who die in the casualty and reception departments before admission to the wards. We have been very strict in applying the Avery Jones rules to our selection of cases and have included all related deaths such as those due to chronic pyelonephritis or pulmonary embolism.

\section{MORTALITY TRENDS IN THE UNITED KINGDOM DURING THE PRESENT CENTURY}

It is important when comparing mortality from haematemesis to know the type of population involved and the changes which have taken place in the distribution of peptic ulcer in this population between the times of different series. Thus between 1902 and 1907 ulcer mortality in Great Britain was apparently $7 \%$ or under. Many of the low figures came from individually interested physicians from teaching hospitals and at that time the elderly and indigent tended to go to county and municipal hospitals. In this connexion it may be noted that one-third of Avery Jones' patients at the Middlesex County hospitals were over 60 (Avery Jones, 1956) whereas the former voluntary hospital series had only shown $10 \%$ in this age group. Also, in the early years of the century, there was a greater proportion of acute ulcers among young women and a smaller one of chronic duodenal ulcers in men over 40 years. All the articles at this time described only the patients admitted to and kept in the medical wards. Between 1920 and 1932 relatively high mortalities were published, of which Bulmer's figure of $10.7 \%$ at the Birmingham General Hospital in 1932 could be regarded as representative (Bulmer, 1932). When overall hospital figures are given (Chiesman, 1932) mortalities of up to $25 \%$ were revealed.

\section{RESULTS}

As the aim of this paper is to assess the mortality from haemorrhage due to peptic ulcer in a series of patients treated with intragastric milk drip, no attempt is made to assess the overall mortality of all patients admitted to hospital with such haemorrhage. There is therefore some unavoidable selection of cases. A number of patients were excluded as the milk drip was not used. Fifty-three of these cases were controls in a previous trial and in the others the milk drip was not used for a variety of reasons. Among these may be mentioned refusal by the patient, associated disease such as respiratory infection, and the contraindications noted above.

When trying to apply Avery Jones' Goulstonian rules to the outcome of haemorrhage treated by continuous intragastric milk drip and a generous Meulengracht diet we were faced with the difficulty of what to do with patients who rejected the drip at an early stage. A few patients returned their tube with bloody vomit almost as soon as it had been put down. After doing this once or twice the tube was removed as it was felt that persistence with this form of treatment would only lead to continued bleeding. Very often these were patients with brisk recurrent haemorrhage for whom the outlook with purely medical measures was not good and in whom surgery was often considered. We ultimately decided to exclude patients who did this repeatedly during the first 12 hours and who could be fairly said to have had very little milk and no opportunity to start a puree diet. Because of the difficulty of this sort of decision, however, we also include such patients in a second set of results in which the overall mortality is $6.1 \%$, still a reasonably low figure at the present time. The proportion of peptic ulcer patients among the overall cases of haematemesis or melaena admitted to the wards as emergencies between June 1950 and January 1962 is shown in Table II. It may be noted that peptic ulcer accounted for 517 out of $580(87 \%)$ of all cases of haematemesis and melaena.

Table III analyses the cases with peptic ulcer 
TABLE II

TOTAL EMERGENCY ADMISSIONS FOR HAEMATEMESIS OR MELAENA FROM JUNE 1950 TO JANUARY 1952

Peptic ulcer

Haematemesis. .....438

Melaena only .... 79

Carcinoma of stomach

Cirrhosis of liver (oesophageal varices)

Telangiectasis

Haemophilia

Uraemia

Leiomyoma

Scurvy

Thrombocytopenic purpura

Haemorrhagic thrombocythaemia

Carcinoma of oesophagus

Cases discharged against medical advice

before adequate investigation

Total

TABLE III

ANALYSIS OF HAEMORRHAGE FROM PEPTIC ULCERATION $1950-62$

\begin{tabular}{lcc} 
& $\begin{array}{l}\text { Excluding Cases } \\
\text { with Melaena } \\
\text { Only }\end{array}$ & $\begin{array}{l}\text { All Forms of } \\
\text { Haemorrhage }\end{array}$ \\
\hline $\begin{array}{l}\text { All cases } \\
\begin{array}{l}\text { Cases in which drip was } \\
\text { not used at all }\end{array}\end{array}$ & 438 & 517 \\
$\begin{array}{l}\text { Cases in which drip was } \\
\text { erected but discontinued } \\
\text { in less than 12 hours }\end{array}$ & 75 & 87 \\
$\begin{array}{l}\text { Total cases included in series } \\
\text { i.e., all cases with drip for } \\
\text { longer than 12 hours }\end{array}$ & 4 & 5 \\
\end{tabular}

TABLE IV

SEX INCIDENCE AND MORTALITY IN DRIP CASES ONLY

\begin{tabular}{|c|c|c|c|c|c|c|c|c|}
\hline & \multicolumn{4}{|c|}{$\begin{array}{l}\text { Haematemesis (Excluding Patients with } \\
\text { Melaena Only) }\end{array}$} & \multicolumn{4}{|c|}{$\begin{array}{l}\text { All Types of Haemorrhage from } \\
\text { Peptic Ulcer }\end{array}$} \\
\hline & $\boldsymbol{M}$ & $\boldsymbol{F}$ & Total & Deaths & $M$ & $F$ & Total & Deaths \\
\hline Duodenal ulcer & 155 & 45 & 200 & 10 & 182 & 61 & 243 & 11 \\
\hline Gastric ulcer & 23 & 8 & 31 & 3 & 28 & 11 & 39 & 3 \\
\hline Gastric and duodenal ulcers & 6 & 1 & 7 & 0 & 7 & 1 & 8 & $\mathbf{0}$ \\
\hline Acute lesion & 53 & 42 & 95 & 3 & 62 & 41 & 103 & 3 \\
\hline Stomal ulcer & 11 & 2 & 13 & 3 & 13 & 3 & 16 & 4 \\
\hline Oesophageal ulcer & 4 & 7 & 11 & $\mathbf{0}$ & 4 & 10 & 14 & $\mathbf{0}$ \\
\hline Duodenal and oesophageal ulcers & 1 & 1 & 2 & 0 & 1 & 1 & 2 & 0 \\
\hline Totals & 253 & 106 & 359 & $\begin{array}{c}19 \\
(5 \cdot 3 \%)\end{array}$ & 297 & 128 & 425 & $\begin{array}{c}21 \\
(4 \cdot 9 \%)\end{array}$ \\
\hline $\begin{array}{l}\text { Totals including those who had drip } \\
\text { less than } 12 \text { hours }\end{array}$ & 254 & 109 & 363 & $\begin{array}{c}23 \\
(6 \cdot 3 \%)\end{array}$ & 299 & 131 & 430 & $\begin{array}{c}26 \\
(6.0 \%)\end{array}$ \\
\hline
\end{tabular}

TABLE V

DISTRIBUTION OF AGE GROUPS

\begin{tabular}{|c|c|c|c|c|c|c|c|c|c|c|c|c|}
\hline \multirow[t]{4}{*}{ Age } & \multicolumn{8}{|c|}{$\begin{array}{l}\text { Continuous Milk Drip, Generous Feeding, and Adequate } \\
\text { Drip Transfusions in Present Series (1950-62) }\end{array}$} & \multirow{3}{*}{\multicolumn{2}{|c|}{$\begin{array}{l}\text { Restricted Fluid } \\
\text { Intake and } \\
\text { Occasional Small } \\
\text { Transfusions in } \\
\text { Haematemesis Only } \\
\text { (Cullinan and Price, } \\
\text { 1932) }\end{array}$}} & \multirow{2}{*}{\multicolumn{2}{|c|}{$\begin{array}{l}\text { Generous Feeding, } \\
\text { Witt's Regime, and } \\
\text { Adequate Transfusions } \\
\text { in Haematemesis Only } \\
\text { (Avery Jones, 1947) }\end{array}$}} \\
\hline & \multicolumn{4}{|c|}{ Haematemesis Only } & \multicolumn{4}{|c|}{$\begin{array}{l}\text { All Types of Haemorrhage from } \\
\text { Peptic Ulcer }\end{array}$} & & & & \\
\hline & \multirow[t]{2}{*}{ No. } & \multirow[t]{2}{*}{$\%$} & \multirow[t]{2}{*}{ Deaths } & \multirow{2}{*}{$\underset{\%}{M o r t a l i t y}$} & \multirow[t]{2}{*}{ No. } & \multirow[t]{2}{*}{$\%$} & \multirow[t]{2}{*}{ Deaths } & \multirow{2}{*}{$\underset{\%}{\text { Mortality }}$} & & & & \\
\hline & & & & & & & & & No. & Deaths & No. & Deaths \\
\hline $10-19$ & 9 & $2 \cdot 5$ & 0 & 0 & 9 & $2 \cdot 1$ & 0 & 0 & 1 & 0 & 1 & 0 \\
\hline $20-29$ & 38 & 10.6 & 0 & 0 & 43 & $10 \cdot 1$ & 0 & 0 & 12 & 0 & 29 & 1 \\
\hline 30-39 & 50 & 13.9 & 1 & $2 \cdot 0$ & 58 & 13.7 & 1 & 1.7 & 15 & 3 & 72 & 1 \\
\hline $40-49$ & 79 & 22.0 & 1 & $1 \cdot 3$ & 93 & 21.9 & 1 & $1 \cdot 1$ & 29 & 6 & 118 & 3 \\
\hline $50-59$ & 78 & $21 \cdot 7$ & 3 & 3.8 & 91 & $21 \cdot 4$ & 3 & $3 \cdot 3$ & 37 & 6 & 128 & 7 \\
\hline $60-69$ & 63 & 17.6 & 8 & $12 \cdot 7$ & 78 & $18 \cdot 4$ & 8 & $10 \cdot 3$ & 11 & 4 & 109 & 15 \\
\hline $70-79$ & 34 & 9.5 & 6 & $17 \cdot 7$ & 44 & $10 \cdot 3$ & 8 & 18.2 & - & - & 61 & 12 \\
\hline Over 80 & 8 & $2 \cdot 2$ & 0 & 0 & 9 & $2 \cdot 1$ & 0 & 0 & - & - & 12 & 3 \\
\hline Total & 359 & 100 & 19 & $5 \cdot 3$ & 425 & 100 & 21 & 4.9 & 105 & 19 & 530 & 42 \\
\hline
\end{tabular}

TABLE VI

FATAL CASES

Number Main Causes Haemorrhage

Others

Pulmonary Embolus

\begin{tabular}{lccccc}
\hline Operative deaths & 11 & 3 & 4 & 3 & 1 \\
Non-operative deaths & 10 & 5 & 1 & 1
\end{tabular}


further, giving the total number of patients in whom a milk drip was used for longer than 12 hours.

The sex incidence, ulcer site, and mortality are shown in Table IV.

Table $\mathrm{V}$ shows the distribution of the age groups and compares the mortalities with those of Cullinan and Price (1932) and Avery Jones (1947). It will be seen that the present figures are divided into two groups, those referring to haematemesis only and those referring to all types of haemorrhage from peptic ulcer.

In Table VI the 21 fatal cases in the 425 driptreated patients are classified. Among miscellaneous causes may be noted bronchopneumonia (three out of six cases), uraemia (one case), left ventricular failure due to aortic stenosis (one case), and mesenteric thrombosis (one case). Among the patients dying of haemorrhage, the three patients treated surgically continued to bleed post-operatively and necropsy showed that in each case haemostasis had not been adequately secured. The other surgical deaths were, it was felt, due to purely surgical complications rather than a direct result of haemorrhage. In the non-operative group several factors may be mentioned. One patient had simultaneous perforation of a peptic ulcer, and four patients died of indirectly related causes, which are noted at the beginning of this paragraph. They, have, however, been included as they come under the heading of deaths following haematemesis according to Avery Jones' criteria. Of the patients not operated on dying of haemorrhage, three can be said to have died of haemorrhage alone without any additional factors being present and one of these died as a result of rupture of an aneurysm of the splenic artery in the base of an ulcer. The surgical mortality was considerably greater than the overall mortality, and we may ask ourselves whether our bias towards medical treatment would contribute by delaying the time of operation. In fact, although a low total of patients was operated upon, when a decision was made to operate this was within the first 48 hours in approximately half the cases, and within the first week in all except two. In patients under 60 , a mortality of $1.7 \%$ was recorded in two present series.

\section{DISCUSSION}

HOW IS MORTALITY FROM PEPTIC ULCER HAEMORRHAGE TO BE FURTHER REDUCED AT THE PRESENT TIME? We believe that the factors leading to diminished mortality since 1932 have been an improved use of blood transfusion coupled with more ready availability of blood; improved medico-surgical collaboration with an early decision to operate when indicated; improved facilities for the biochemical and haematological assessment of the fluid, electrolyte, protein, and blood losses taking place; a more generous attitude to early feeding, and early diagnosis of the cause of bleeding.

Blood transfusions It is an idea which is still held by some clinicians that generous transfusion leads to the recommencement of bleeding. As recently as 1948 Andresen advised limited transfusion and restricted fluids during the first 10 days. In 1935, Marriott and Kekwick described techniques of continuous blood transfusion in haemorrhage caused by peptic ulcer, and it has now become usual to replace blood in adequate amounts to treat shock and bring the patient to a safe state so that he can withstand possible operation and further haemorrhage. As Tibbs (1960) points out, more rapid transfusion techniques are sometimes indicated, particularly when emergency surgery is contemplated.

Medico-surgical collaboration Joint supervision of patients with peptic ulcer haemorrhage by both physician and surgeon is desirable. This supervision should be particularly close in the first 48 hours after admission. Finsterer (1936) urged the importance of early operation where there was known ulceration and recurrent haemorrhage and was able to point to higher mortalities if operation was delayed. His views have been re-emphasized in Great Britain by Gordon-Taylor (1937), Tanner (1951), Ogilvie, Cardoe, and Bentley (1952), and Tibbs (1960). It is noteworthy, however, that physicians and surgeons who practice this sort of collaboration cannot bring the mortality figure much below 5 to $7 \%$, and Avery Jones (1956) reporting a mortality of $7 \cdot 7 \%$ in 1,764 cases seen between 1941 and 1954, felt that further resort to surgery could not have reduced the figure. However, Avery Jones' series has been further extended to include a total of 2,302 cases (Avery Jones and Gummer, 1960; Chandler, 1960). Over the three-year period 1955 to 1957 the mortality figure for haematemesis and melaena fell markedly to $4.1 \%$, giving a total mortality of $6.8 \%$ in the 2,302 cases. It was felt that the reduction in mortality between 1955 and 1957 was due to the adoption of selective surgical treatment at the Central Middlesex Hospital, aided by early diagnosis of the cause of haemorrhage.

Biochemical and haematological investigations We need hardly stress the more readily available biochemical investigations compared with the position in the early part of this century. In recent years the part played by electrolyte imbalance in precipitating or potentiating ileus has been recognized. The ability to detect and treat such imbalance rapidly must have prevented many deaths.

Generous feeding measures Although Lenhartz 
(1904) advised feeding with milk and raw eggs from the first day, it was the custom in the United Kingdom before 1927 to starve patients during the first three days on a Sippy regime when ice was given to suck and fluids were withheld. Many have pointed to the aggravation of shock, anxiety, and discomfort by this sort of regime, and Meulengracht (1934) in particular pointed out the very dubious rationale behind such diets. Following Meulengracht's excellent published mortality of $1 \%$ among ulcer patients treated with early and generous feeding, the Sippy regime has been much less commonly used, but it still has some adherents.

Early diagnosis of the cause of bleeding Many centres are now employing early gastroscopy, barium contrast studies, and early aspiration of the gastric contents to measure intragastric $p \mathrm{H}$. In order to detect acute ulcer erosion or gastrostaxis, determination of urinary pepsinogens may also aid early diagnosis (Janowitz, Levy, and Hollander, 1950). The technique of an early barium meal as elaborated by Hampton (1937) is discussed fully by Chandler, Cameron, Nunn, and Street (1960). These investigations may not be without risk of initiating further haemorrhage and the examination may be inconclusive. Among 238 patients admitted with haematemesis and melaena and studied by immediate hourly gastric aspiration, Chandler and Watkinson have reported only 11 deaths $(4.7 \%)$, a very creditable figure which compares favourably with larger series (Chandler and Watkinson, 1959). The fact that the cause of bleeding has been established within the first 48 hours is obviously of great value as regards future management. Early ambulation may be possible and an early decision may be made about surgery. The only drawback to the vigorous pursuit of these diagnostic procedures is that the regime of early generous feeding and intragastric milk may be interrupted in the first three days when such measures are most important.

PRESENT SERIES We have pursued generous feeding principles to their extremes, combining the diet of Meulengracht with the intragastric milk drip of Winkelstein. We have also adhered as far as possible to the policy of early surgical treatment. Our results show a low mortality in all groups, particularly in cases under 60 years of age despite some postoperative deaths, and vindicates this mode of management.

The overall mortality in this series includes 11 post-operative deaths in 24 cases submitted to surgery These figures compare with a recent series
(Levrat, Lambert, and Martin, 1962) of 500 cases showing four such deaths in 10 patients submitted to early surgery in a series of 500 patients with haemorrhage due to peptic ulcer.

As regards age and sex distribution and site of haemorrhage, our results show the same trends as do other published series.

We would like to express our thanks to Dr. C. N. Armstrong for permission to include in the present series cases admitted under his care at the Queen Elizabeth Hospital, Gateshead and to Dr. T. H. Boon for his helpful comments.

\section{REFERENCES}

Andresen, A. F. R. (1948). Management of gastric hemorrhage. N. Y. St. J. Med., 48, 603-606.

Ashby, D. W., and Whitehouse, D. (1955). Treatment of haemorrhage from peptic ulcer by continuous intragastric milk drip. Brit. med. J., 1, 512-515.

Bulmer, E. (1932). Mortality from haematemesis; a supplementary analysis. Lancet, 2, 720-722.

Chandler, G. N. (1960). The treatment of haematemesis. Postgrad. med. J., 36, 762-767.

- Cameron, A. D., Nunn, A. H., and Street, D. F. (1960). Early investigations of haematemesis. Gut, 1, 6-13.

- , and Watkinson, G. (1959). The early diagnosis of the causes of haematemesis. Quart. J. Med., 28, 371-395.

Chiesman, W. E. (1932). Mortality of severe haemorrhage from peptic ulcers. Lancet, 2, 722-723.

Cullinan, E. R., and Price, R. K. (1932). Haematemesis following peptic ulceration: prognosis and treatment. St. Barts. Hosp. Rep., 65, 185-213.

Finsterer, H. (1936). Operative treatment of severe gastric haemorrhage of ulcer origin. Lancet, 2, 303-305.

Gordon-Taylor, G. (1937). The problem of the bleeding peptic ulcer. Brit. J. Surg., 25, 403-425.

Hampton, A. O. (1937). A safe method for the roentgen demonstration of bleeding duodenal ulcers. Amer. J. Roentgenol., 38, 565-570.

Janowitz, H. D., Levy, M. H., and Hollander, F. (1950). The diagnostic significance of urinary pepsinogen excretion in diseases of the upper gastrointestinal tract. Amer. J. med. Sci., 220, 679-682.

Jones, F. Avery. (1947). Haematemesis and melaena, with special reference to bleeding peptic ulcer. Brit. med. J., 2, 441-446, and 477-482.

(1956). Haematemesis and melena with special reference to causation and to the factors influencing the mortality from bleeding peptic ulcers. Gastroenterology, 30, 166-190.

Blackwells, Oxford.

Lenhartz, H. (1904). Eine neue Behandlung des ulcus ventricul. Dsch. med. Wschr., 30, 412-413.

Levrat, M., Lambert, R., and Martin, F. (1962). Etiologic factors in 500 cases of bleeding peptic ulcer. Amer. J. dig. Dis., 7, 817-823.

Marriott, H. L., and Kekwick, A. (1935). Continuous drip blood transfusion. Lancet, 1, 977-981.

Meulengracht, E. (1934). Treatment of hematemesis and melaena with food. Acta med. scand., suppl., 59, 375-385.

Ogilvie, A. G., Cardoe, N., and Bentley, F. H. (1952). Treatment of massive bleeding from peptic ulcer. Brit. med. J., 2, 304-309.

Tanner, N. C. (1951). Oesophageal ulcer and the treatment of the complications of peptic ulcer. Edinb. med. J., 58, 293-304.

Tibbs, D. J. (1960). Selective surgery for gastroduodenal haemorrhage. Brit. med. J., 2, 1346-54.

Winkelstein, A. (1933). A new therapy of peptic ulcer; continuous alkalinized milk drip into the stomach. Amer.J. med. Sci., 185, 695-703. 